\title{
Formulation of SrO-MBCUS Agglomerates for Esterification and Transesterification of High FFA Vegetable Oil
}

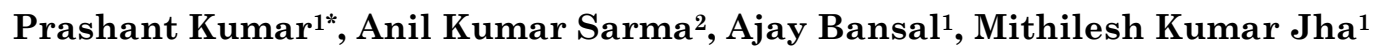 \\ ${ }^{1}$ Department of Chemical Engineering, Dr B. R Ambedkar NIT Jalandhar, Jalandhar, \\ Punjab-144011, India \\ ${ }^{2}$ Chemical Conversion Division, Sardar Swaran Singh National Institute of Renewable Energy, \\ Kapurthala, Punjab-144601, India
}

Received: 19th August 2015; Revised: 8 ${ }^{\text {th }}$ December 2015; Accepted: 1't January 2016

\begin{abstract}
Musa Balbisiana Colla Underground Stem (MBCUS) catalyst was treated thermally mixing with 5:1 $\mathrm{w} / \mathrm{w}$ of Strontium Oxide ( $\mathrm{SrO})$ and the dynamic sites were reformed. The MBCUS-SrO showed sharper crystalline phases as evidence from XRD and TEM analysis. The composition and morphology were characterized from BET, SEM, EDX thermo-gravimetric analysis (TGA) and XRF analysis. The optimization process for biodiesel production from Jatropha curcas $L$ oil (JCO) having high percentage of free fatty acids was carried out using orthogonal arrays adopting the Taguchi method. The linear equation was obtained from the analysis and subsequent biodiesel production (96\% FAME) was taken away from the JCO under optimal reaction conditions. The biodiesel so prepared had identical characteristics to that with MBCUS alone, but at a lower temperature $\left(200{ }^{\circ} \mathrm{C}\right)$ and internal vapour pressure. Metal leaching was much lower while reusability of the catalyst was enhanced. It was also confirmed that the particle size has little impact upon the conversion efficacy, but the basic active sites are more important. Copyright (C) 2016 BCREC GROUP. All rights reserved
\end{abstract}

Abstract

Keywords: Catalysis; MBCUS-SrO agglomerates; transesterification; active basic sites; biodiesel; Taguchi method

How to Cite: Kumar, P., Sarma, A.K., Bansal, A., Jha, M.K. (2016). Formulation of SrO-MBCUS Agglomerates for Esterification and Transesterification of High FFA Vegetable Oil. Bulletin of Chemical Reaction Engineering \& Catalysis, 11 (2): 140-150 (doi:10.9767/bcrec.11.2.540.140-150)

Permalink/DOI: http://dx.doi.org/10.9767/bcrec.11.2.540.140-150

\section{Introduction}

Heterogeneous catalysis for transesterification of triglycerides emerged as a new field of research in recent past for biodiesel production from vegetable oil or fats $[1,2]$. Among the

* Corresponding Author.

E-mail: prashant.kumar87@gmail.com

(P. Kumar), Telp.: +91-9452538858 solid acid catalytic transesterification, sulfated zirconium [3] and 12-tungstophosphoric acid supported on $\mathrm{SnO}_{2}$ [4] could be effective as described in literatures. Strontium oxide ( $\mathrm{SrO})$ has been regarded as a very effective one among the base heterogeneous catalyst for transesterification with about $96 \%$ conversion of cooked oil to biodiesel under microwave radiation at $1 \%$ loading $[5,6]$. Nevertheless, the monetary value of pure $\mathrm{SrO}$ is very high and reusability is another shortage of this stuff. 
As background information, biodiesel is made from vegetable oils or animal fats through transesterification reaction which uses alcohols in the presence of a catalyst that assist chemically breaks the molecules of triglycerides into alkyl esters (i.e. biodiesel) [7-8]. The commonly used alcohols for the transesterification include methyl alcohol and ethyl alcohol. Methyl alcohol is most frequently used, due to its low price and high activity [5]. Low grade vegetable oil having high percentage of free fatty acids (FFA) or high moisture contents requires especially catalytic elevated temperature reaction for conversion to biodiesel [7-10]. Furthermore, the factors which affect the process of transesterification are many viz. quality and composition of the oil, type of alcohol, oilalcohol molar ratio, type and amount of catalyst, reaction time, reaction temperature, stirring speed, etc. [11, 12].

Very recently, waste derived materials have been drawn in several literatures for the transesterification of vegetable oil [9-10], [13-14]. We reported a Musa balbisiana Colla underground stem (MBCUS) nano-material and its application for biodiesel production from high free fatty acid containing jatropha curcas L oil (JCO) and Meusa ferrea L oil in a single step under elevated condition. The MBCUS was found effective at just about $275{ }^{\circ} \mathrm{C}$ and $1: 9$ oilalcohol molar ratio and up to $98 \%$ ester could be recovered. The product separation, mechanism of catalytic effects and leaching of the metal ions were studied in particular [9-10]. There is a general tendency to increase the catalytic efficacy of the MBCUS, because it can be easily prepared from an agricultural waste. The experimental optimization of several factors during the transesterification was reported in several literature via Response Surface Methodology [15], Taguchi's Method [16], etc.

In this approach, we prepared hybrid nature heterogeneous catalyst of $\mathrm{SrO}$ and MBCUS. The MBCUS-SrO preparation, characterization using different techniques, e.g. thermogravimetric analysis (TGA), SEM, TEM, XRD, XRF, BET surface area, including structural dimensions and application for the transesterification of JCO having a high percentage of free fatty acids have been reported. The Taguchi approach was used in this field, with the orthogonal array design used to screen the effects of four parameters, i.e., the molar proportion of alcohol to oil, reaction time, catalyst concentration and reaction temperature, for the production of JCO at five-storey. Further, the optimum reaction was carried out and reported. A few significant findings have been identified in this work, how the catalytic efficacy increases with the doping and formulation of the MBCUS-SrO during transesterification, the change in structure and crystalline nature, stability, reactivity and so along.

\section{Materials and Methods}

\subsection{Materials}

The JCO used for the design of experimental work was procured from an oil marketing company of Rajsthan, India. The JCO used to have acid value $18.4 \mathrm{mg} \mathrm{KOH} / \mathrm{g}$ oil, while the initial water content was $759 \mathrm{ppm}$ and used as such without further characterization as the same was properly stored and applied within a month time span. Although this JCO contains different fatty acids of varying chain lengths and different degree of unsaturation, yet it has four major fatty acids, namely: $32.3 \%$ linoleic acid (C18:2), 38.0\% oleic acid (C18:1), $16.9 \%$ palmitic acid (C16:0) and $8.6 \%$ stearic acid (C18:0).

\subsection{Catalyst preparation}

The MBCUS material was obtained as per our previous publication $[9,18]$. MBCUS nano material was thermally modified using strontium oxide (99.9\% Purity). SrO was blended with MBCUS ash catalyst in 1:5 ratio by weight, i.e. $1 \mathrm{~g}$ strontium oxide to $5 \mathrm{~g}$ MBCUS catalyst, and named as MBCUS-SrO. This blend was further treated thermally in a muffle furnace for $1 \mathrm{~h}$ at $550{ }^{\circ} \mathrm{C}$, cooled in desiccators and stored.

\subsection{Characterization of catalyst}

The MBCUS-SrO was characterized using $\mathrm{XRD}, \mathrm{XRF}, \mathrm{BET}$ surface area using nitrogen, thermo-gravimetric analysis (TGA), SEM and TEM. The powder X-ray diffraction analysis was carried out by using a PANalytical X'Pert Pro. The diffractometer employing $\mathrm{Cu}-\mathrm{Ka}$ radiation to generate diffraction patterns from powder crystalline samples at ambient temperature. The $\mathrm{Cu}-\mathrm{Ka}$ radiation was generated by Philips glass diffraction, X-ray tube broad focus $2.7 \mathrm{~kW}$ type. All samples were mounted on samples holder and the basal spacing was determined via powder technique.

The total surface area of the catalysts was obtained by the BET method using nitrogen adsorption at $-195.850{ }^{\circ} \mathrm{C}$. The analysis was conducted using Micromeritics ASAP 2020 series using nitrogen adsorption/desorption analyzer. The scanning electron microscopy with energy dispersive X-ray detector (SEM-EDS) technique 
was applied to hold the information on the morphology and elemental composition of the samples. The morphology of the catalysts was studied using a FE-SEM QUANTA 200 FEG from FEI Netherlands. The samples were coated with gold using a sputter coater. The elemental composition was analyzed by using an energy dispersive X-ray detector (EDS) mounted on the microscope. TEM observations were done with a TEM TECNAI G 20 S-TWIN (FEI Netherlands) electron microscope. A drop of the sample suspension diluted in alcohol was put onto a holey carbon film supported by a $3-\mathrm{mm}$ copper grid and then observed.

The thermal stability of the catalyst was studied by using a thermo-gravimetric Analyzer (TGA) manufactured by Perkin Elmer, model STA 6000 for thermal and oxidative stability. The weight losses of the catalyst (prepared at $550{ }^{\circ} \mathrm{C}$ ), temperature range $30-$ $1,000{ }^{\circ} \mathrm{C}$, heating rate $10{ }^{\circ} \mathrm{C} / \mathrm{min}$ and constant flow of air and nitrogen $(20 \pm 0.5 \mathrm{ml} / \mathrm{min})$ were recorded. The composition of the catalyst was determined by X-ray Florescence technique with Wavelength Dispersive X-ray Fluorescence-S8 Tiger from Bruker, Germany.

The basic strength of the catalysts $(\mathrm{H}-)$ was determined using Hammett indicator method. Approximately $100 \mathrm{mg}$ of the catalyst sample was shaken with an appropriate amount of Hammett indicators diluted with methanol and left to equilibrate for $2 \mathrm{~h}$ until no further colour change was observed. The colour of titrate was then recorded. The following Hammett indicators were used: neutral red $\left(\mathrm{H}_{-}=6.8\right)$, bromothymol blue $\left(\mathrm{H}_{-}=7.2\right)$, phenolphthalein $\left(\mathrm{H}_{-}=\right.$ 9.3), 2,4-dinitroaniline $\left(\mathrm{H}_{-}=15.0\right), \quad 4$ nitroaniline $\left(H_{-}=18.4\right)$. The base strength of the catalysts was defined as being stronger than the Hammett indicator if it showed a colour change but weaker if it showed no colour change.

\subsection{Design of experiment for the optimiza- tion of transesterification process}

An experimental design methodology adopting the Taguchi approach was employed in this study, with the orthogonal array design to screen the effects of four parameters, having in the molar ratio of alcohol to oil, reaction time, catalyst concentration and reaction temperature during the production of Jatropha methyl esters (JCO FAME). These four selected parameters were experimentally studied at fivelevels, i.e. L-25. The diversity factors were studied by crossing the orthogonal array of the control param-eters (Table 1).

In this study, Minitab 16, which is a software for the Automatic Design and Analysis of Taguchi Experiments, was used to analyse the results and optimize the experimental conditions for determining the control variables.

\subsection{Analysis of catalytic activity of trans- esterification reaction}

The reactions were carried out in a HPHT Bench Top Batch reactor of 1.8 L capacity (Amar equipments Company, Mumbai, India). The transesterification reaction was performed by altering reaction temperature, oil to methanol molar ratio, reaction time and catalyst percentage. The impeller speed was set at 550 RPM. Initially no pressure was applied to the reaction system which raised up to $3.2 \times 10^{6} \mathrm{~Pa}$ with increasing internal vapor pressure at 200 ${ }^{0} \mathrm{C}$. The samples were collected after rapid cooling of the reactor using its integrated cooling system. Then, samples were taken by opening the sampling value. The samples collected from the reactor were allowed to settle in a ventilator before analysis. Since triglycerides, diglycerides, monoglycerides and free fatty acids (FFAs) analysis relates only with the oily liquid phase of the sample and the results are presented as percentage of the total oily mass, the oily mass was purged of impurities that might affect the final measurements. So, the oily phase was later transferred to the rotary vacuum evaporator (Heydolph, Germany Make) and the unreacted methanol was separated in $45-50{ }^{\circ} \mathrm{C}$ and $2.25 \times 10^{3} \mathrm{~Pa}$. Then, the samples were centrifuged to separate the catalyst, glycerine (GL) and oily phase. The upper layer of the centrifuged sample consists of the oily

Table 1. Design of experiments, with four parameters at five-level, for the transesterification of JCO

\begin{tabular}{lccccc}
\hline \multicolumn{1}{c}{ Parameter (Symbol) / Level } & 1 & 2 & 3 & 4 & 5 \\
\hline Catalyst percentage (A) & 1 & 2 & 3 & 4 & 5 \\
Temperature (B) & 150 & 175 & 200 & 225 & 250 \\
Alcohol to oil molar ratio (C) & 3 & 6 & 9 & 12 & 15 \\
Reaction time (minute) (D) & 15 & 30 & 45 & 60 & 75 \\
\hline
\end{tabular}


phase (biodiesel), the lower one of the GL, while in the middle, between the oil and the glycerine phase appears the catalyst. The process flow diagram has been depicted in Figure 1. The catalyst was later washed using petroleum ether and methanol to remove the bound ester and glycerol.

\subsection{Biodiesel analysis by GC}

The biodiesel prepared were studied using Agilent make Gas Chromatograph (GC). The methodology used for biodiesel analysis was similar to our recent articles $[9,17]$.

\subsection{Fuel characteristic analysis of the bio- diesel}

The fuel properties of the biodiesel obtained were analyzed using appropriate ASTM D6751 and EN 14214 standard procedure specified for B100 biodiesel stocks. Density of the biodiesel was analyzed as per ASTM D 1250 using ANTON PAAR Austria 5000M, an automatic density meter. Distillation characteristics were studied with Euro Dist System MPS-P Rofa Deutschland GmbH, Germany uses ASTM D 1160 test method. Flash point was obtained with TANAKA JAPAN ACO-7 as per ASTM D

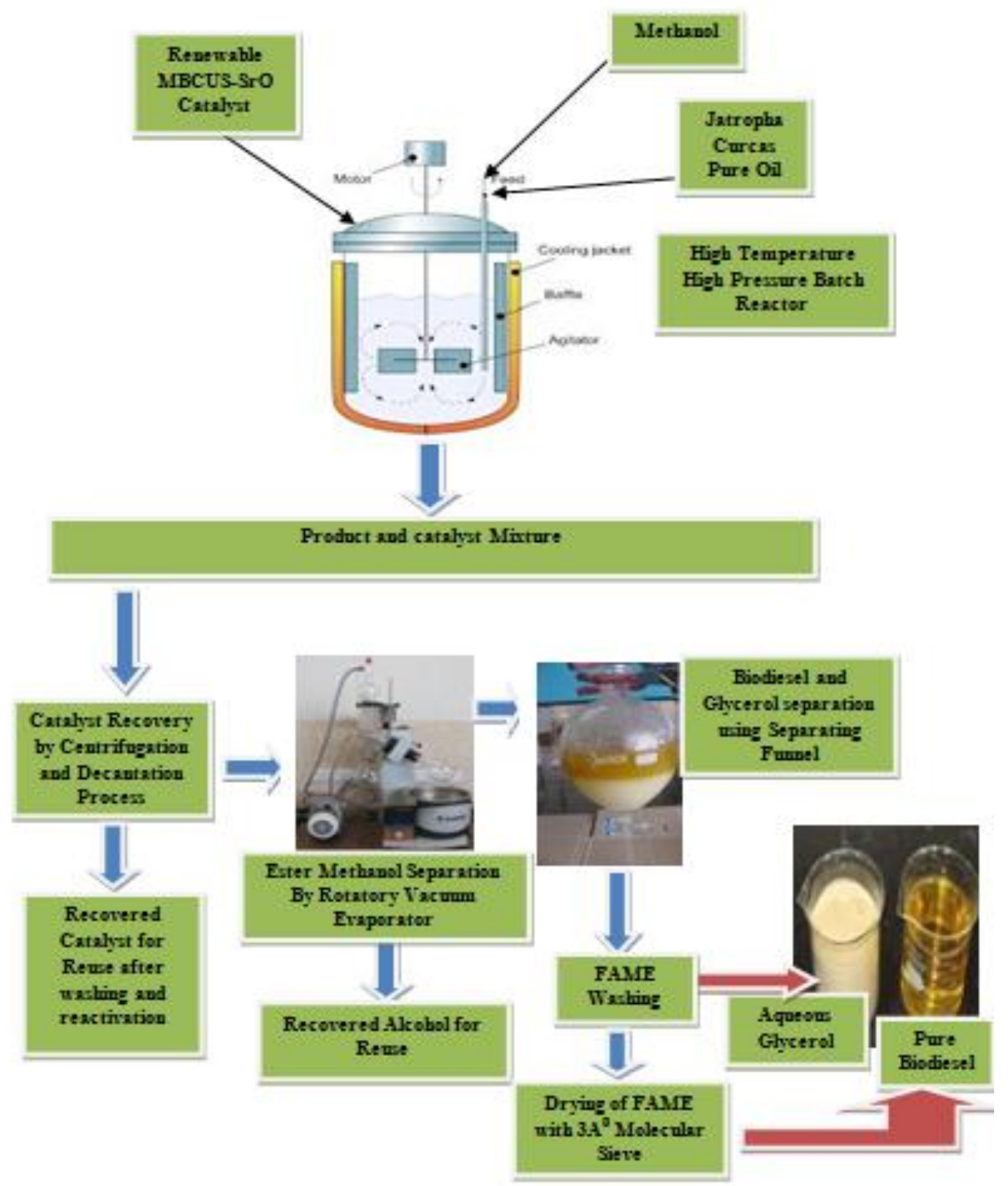

Figure 1. Process flow diagram for biodiesel production using MBCUS-SrO as catalyst under elevated optimized condition 
92. Calorific value was obtained as per IS 1359 with Bomb Calorimeter Toshniwal Technology, CCD 01-M3. Kinematic Viscosity was obtained by Ostowald Viscometer LAWLER Viscometer bath USA 86-18D as per ASTM D 446. Acid Value of the samples was obtained by Titration Method as per ASTM D664. Cetane Number was obtained as per ASTM D613 using CFR Diesel F 5 unit, Waukesha, UK. Ramsbottom carbon residue (wt.\%) was analyzed using ASTM D 524 with SCAIVNI ITLAY Model A00324. Copper Strip Corrosion and Oxidation stability were analysed as per ISO 260 and EN 14112, respectively, with Petrotest DP, Germany and 743 Rancimat-Metrohm AG, Switzerland. Water and Sediment content were analysed by ASTM D 2440 with 90000-2P, Stanhope-Seta, Oil Test Centrifuge, the U.K. Pour point was analysed as per ASTM D 97 with the apparatus made by Lawler manufacturing Corporation, Edison New Jersey. Sulphur content was analysed as per ASTM D 5453 using TN 3000 made by S/N Thermo Electron Corporation. Iodine Value was elaborated by Wij's Method. Sodium and Potassium contain was obtained as per EN 14108 with ICAP Plasma 400, Perkin Elmer Corp. Norwalk, CT. Free Glycerol, Monoglycerides, Diglycerides,
Triglycerides and Total glycerol (free plus bound) were obtained using 7890A model GC supplied by Agilent Technologies as per EN 14106 as per ASTM D6584. The Fatty acid methyl ester (FAME or biodiesel) conversion, expressed as mass percent, has been estimated as per procedure EN 14103. Sulphated ash and total contamination were elaborated as per ASTM D 874 and EN 12662, respectively, using general laboratory apparatus.

\section{Results and Discussion}

\subsection{Characterization of MBCUS-SrO cata- lyst}

The basicity of the catalyst was found within the range of $9.3<\mathrm{H}-<15.0$. The alkalinity of MBCUS-SrO is thus more potent than the weakest indicator phenolphthalein $\left(\mathrm{H}_{-}=9.8\right)$ that showed a colour change from pink to colourless. Nevertheless, it is lighter than the strongest indicator, i.e. 2,4-dinitroaniline $\left(\mathrm{H}_{-}=\right.$ 15.0) as no color change, was observed.

The XRD pattern of the catalyst is shown in the Figure 2. The XRD analysis of the MBCUS$\mathrm{SrO}$ ensures that the presence of sharp peaks at $2 \theta$ in between 19-33, 40-41, 45-46, 58-60, 6667 and 73-74 corresponds to definite crystalline

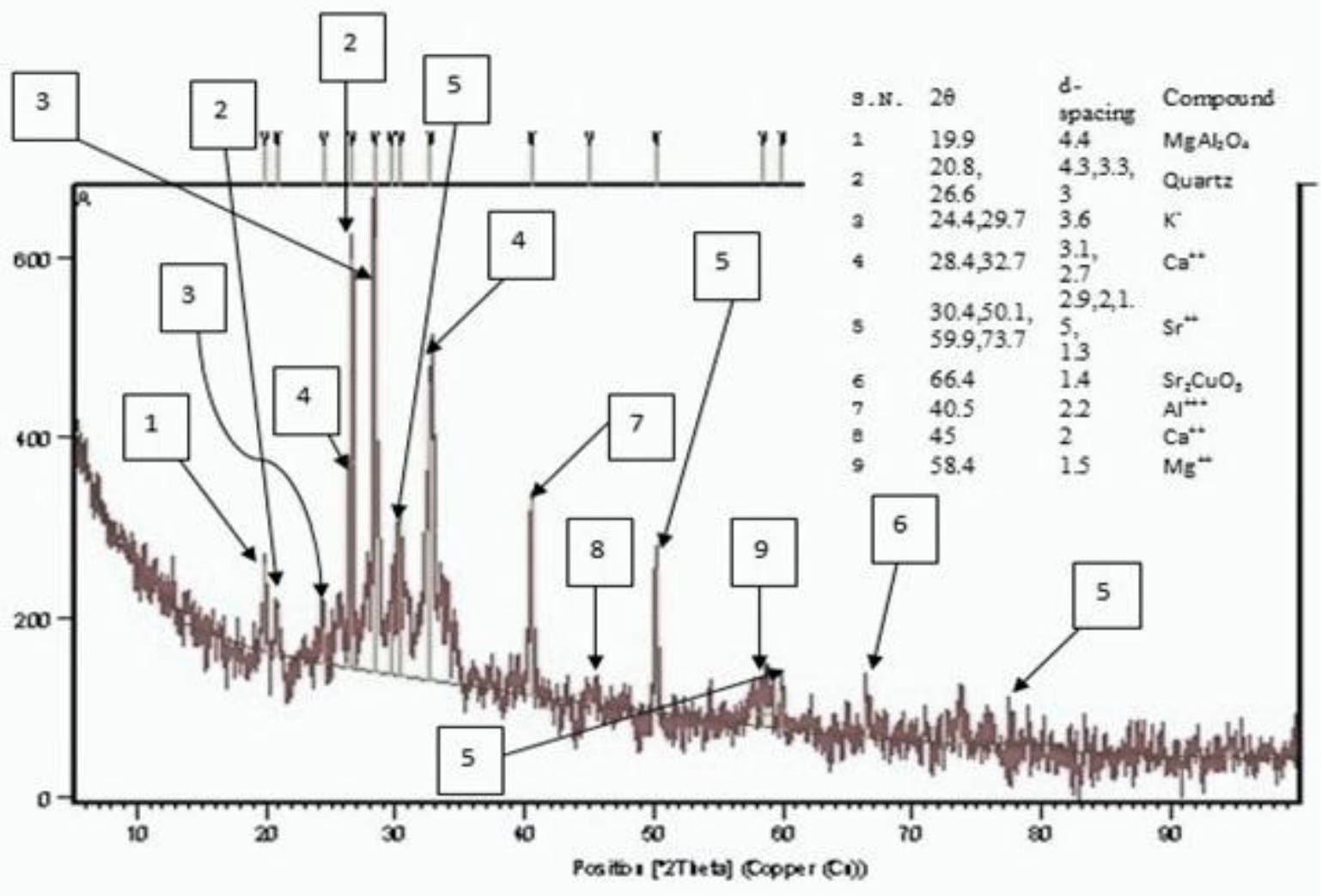

Figure 2. XRD pattern of MBCUS-SrO showing different crystalline phases at specific $2 \theta$ and identification of the components 
phases. These peaks are sharper as compared to MBCUS alone in between 20-35 showing strongly reformed crystalline phases [9,18].

It is affirmed that the BET surface area of the catalyst has been dramatically reduced to $0.043 \mathrm{~m}^{2} / \mathrm{g}$ which is significantly very lower than MBCUS [9, 18] and SrO [24] alone. The total pore volume $0.000825 \mathrm{~cm}^{3} / \mathrm{g}$ for pores is smaller than $7854.3 \AA$ (radius) at P/Po equal to 0.99 and pore size expressed as average pore radius is equal to $2.19 \AA$. The textiles have been found to be macro-porous in nature as well, which have been sustained from the average pore volume. This confirms that MBCUSSrO agglomerated to form a different structure (Figure 3).

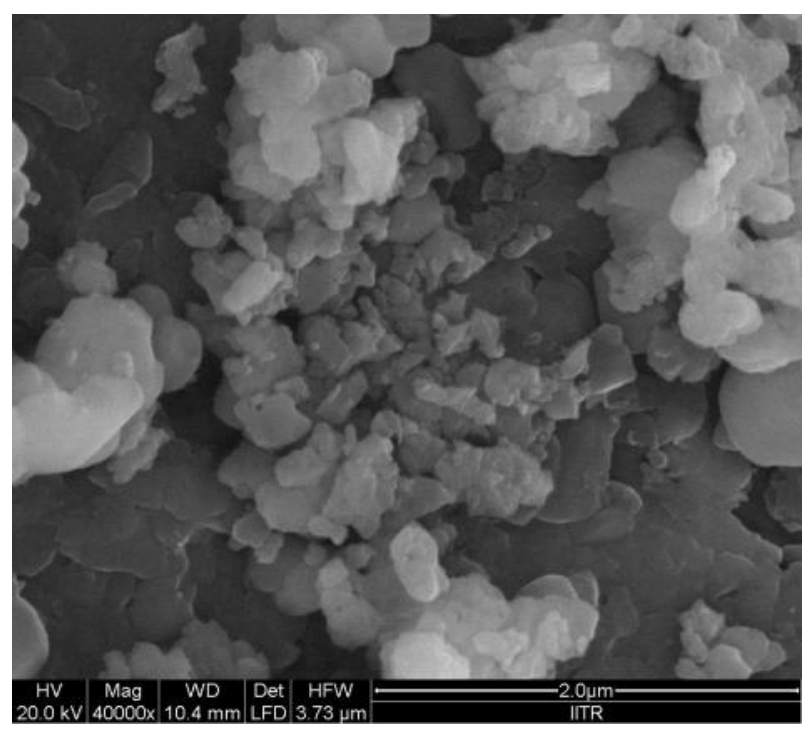

Figure 3. SEM analysis of MBCUS-SrO to depict the surface morphology

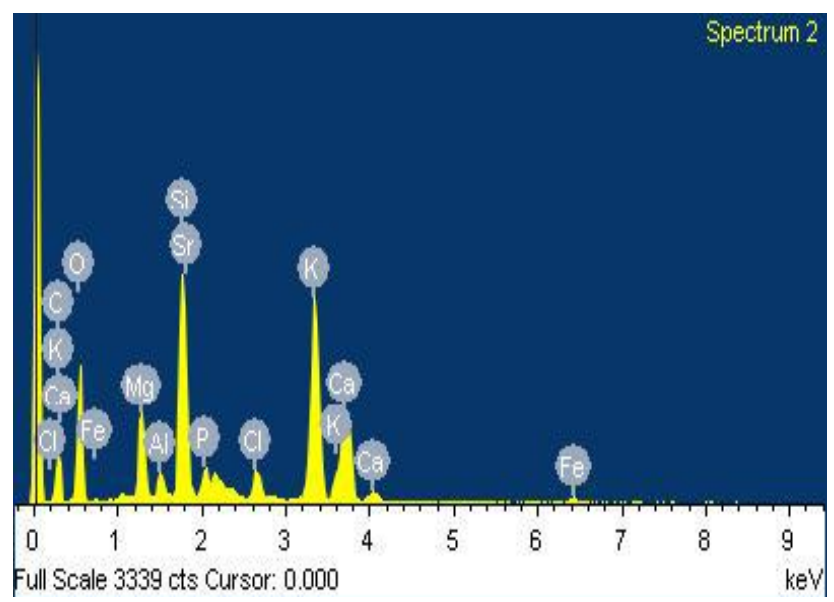

Figure 4. SEM analysis of MBCUS-SrO
The MBCUS-SrO has almost the same composition as MBCUS catalyst, but the amount of strontium oxide increased by $2.86 \%$. The presence of transition metal oxides in trace amount was also detected in the catalyst in addition to chlorides as evidenced from EDX as shown in Figure 4.

The structural information of the catalyst was considered from the TEM images as pictured in the Figure 5. The individual MBCUS$\mathrm{SrO}$ agglomerates showed bigger dimensions viz. 200-500 nm length, but with sharp crystalline phases. Thermal and oxidative stability of the catalyst showed no such considerable distinction from MBCUS alone (Figure 6) as evident from TGA analysis.

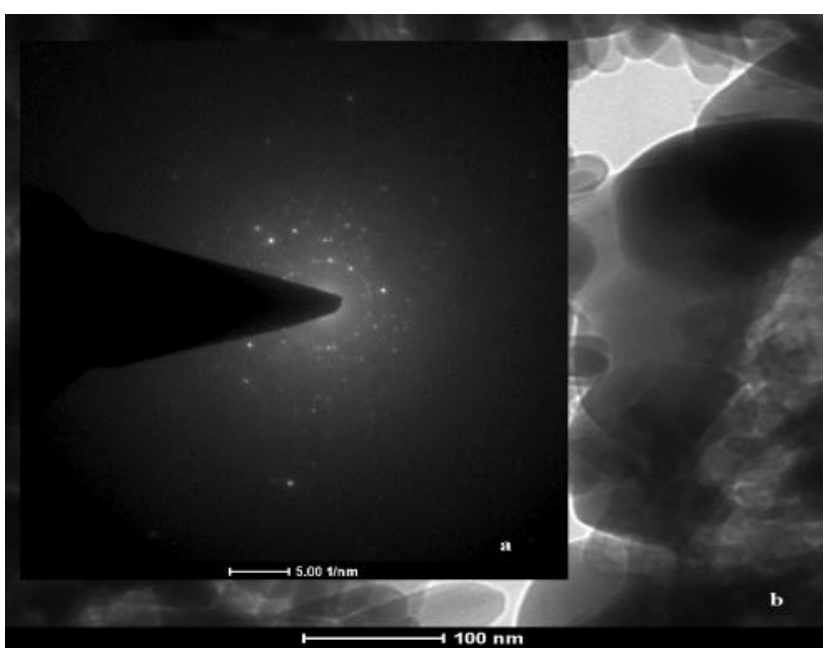

Figure 5. TEM image of MBCUS-SrO Blend a. Sharp crystalline phase identified at $5 \mathrm{~nm}$ scale, b. The agglomerated structure of MBCUS-SrO at $100 \mathrm{~nm}$ scale

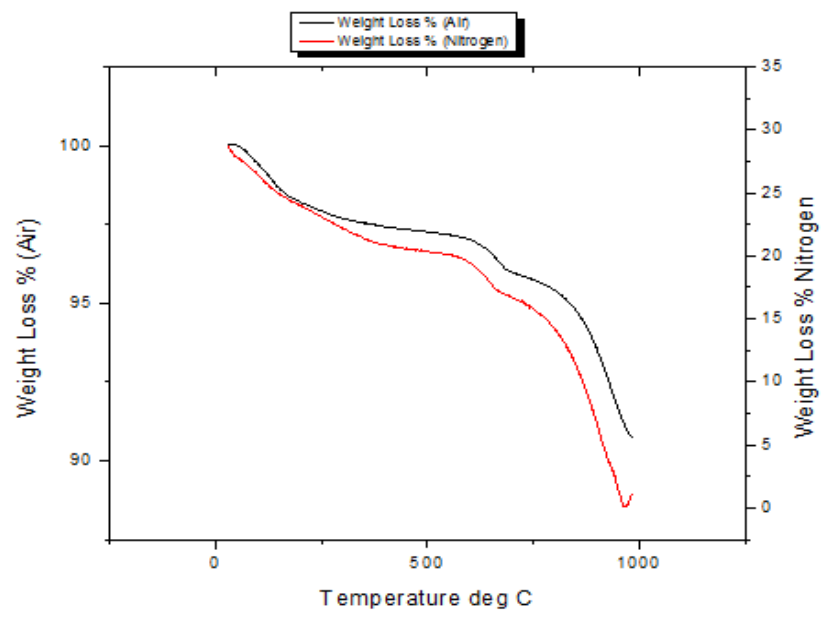

Figure 6. Thermo-Gravimetric Analysis (TGA) graph of MBCUS-SrO under constant nitrogen and air flow to differentiate \%wt. loss with increasing temperature 


\subsection{Process optimization using Taguchi's method}

Taguchi's method stipulates an organized numerical path to evaluate and optimize the process parameters for the production of JCO FAME. Taguchi's Method only uses welldefined sets of experimental for the optimization of the process parameters. The yields of JCO biodiesel ascertained from the gas chromatographic analysis (GC analysis) obtained from the twenty five sets of experiments is presented in Table 2.

All experiments were performed with three repetitions, under the same experimental conditions i.e. molar ratio of alcohol to oil, reaction time, catalyst concentration and reaction tempera-ture. In order to execute the analysis sys- tematically, the proportional importance of each parameter, an analysis of variance (ANOVA) was applied to optimize the results obtained using the Taguchi method. This provided information on the relative influence of parameters and their interactions with respect to the various settlements. According to the ANOVA results (Tables 3 and 4), the most influential parameter in the production of JCO FAME was the catalyst concentration similar to the one described by Hassan and Vinjamur [19].

The signal to noise $(\mathrm{S} / \mathrm{N})$ ratio can be employed to assess the quality characteristic fluctuation from the desired value. Based upon their characteristics the $\mathrm{S} / \mathrm{N}$ ratios are of three different types, i.e. smaller-the-better, larger-the-better and nominal-the-better. The

Table 2. Taguchi's experimental design and corresponding biodiesel yield, error (residual values) and $\mathrm{S} / \mathrm{N}$ ratios"

\begin{tabular}{|c|c|c|c|c|c|c|c|}
\hline S.N. & $\begin{array}{c}\text { Catalyst } \\
\text { Percentage }\end{array}$ & Temperature & $\begin{array}{l}\text { Molar } \\
\text { Ratio }\end{array}$ & $\begin{array}{c}\text { Reaction } \\
\text { Time } \\
\text { (minute) }\end{array}$ & $\begin{array}{l}\text { FAME } \\
\text { Yield }\end{array}$ & Error & S/N Ratio \\
\hline 1 & 1 & 150 & 3 & 15 & 43.69 & 0.48 & 32.81 \\
\hline 2 & 1 & 175 & 6 & 30 & 46.21 & 0.3 & 33.29 \\
\hline 3 & 1 & 200 & 9 & 45 & 48.73 & 0.12 & 33.76 \\
\hline 4 & 1 & 225 & 12 & 60 & 51.25 & 0.06 & 34.19 \\
\hline 5 & 1 & 250 & 15 & 75 & 53.77 & 0.24 & 34.61 \\
\hline 6 & 2 & 150 & 6 & 45 & 56.07 & 0.3 & 34.98 \\
\hline 7 & 2 & 175 & 9 & 60 & 58.59 & 0.12 & 35.36 \\
\hline 8 & 2 & 200 & 12 & 75 & 61.11 & 0.06 & 35.72 \\
\hline 9 & 2 & 225 & 15 & 15 & 61.09 & 0.24 & 35.72 \\
\hline 10 & 2 & 250 & 3 & 30 & 64.55 & 0.12 & 36.20 \\
\hline 11 & 3 & 150 & 9 & 75 & 68.46 & 0.12 & 36.71 \\
\hline 12 & 3 & 175 & 12 & 15 & 68.44 & 0.06 & 36.71 \\
\hline 13 & 3 & 200 & 15 & 30 & 70.96 & 0.24 & 37.02 \\
\hline 14 & 3 & 225 & 3 & 45 & 74.42 & 0.12 & 37.43 \\
\hline 15 & 3 & 250 & 6 & 60 & 76.94 & 0.3 & 37.72 \\
\hline 16 & 4 & 150 & 12 & 30 & 78.30 & 0.06 & 37.88 \\
\hline 17 & 4 & 175 & 15 & 45 & 80.82 & 0.24 & 38.15 \\
\hline 18 & 4 & 200 & 3 & 60 & 84.28 & 0.12 & 38.51 \\
\hline 19 & 4 & 225 & 6 & 75 & 86.80 & 0.3 & 38.77 \\
\hline 20 & 4 & 250 & 9 & 15 & 86.78 & 0.48 & 38.77 \\
\hline 21 & 5 & 150 & 15 & 60 & 86.68 & 0.24 & 39.15 \\
\hline 22 & 5 & 175 & 3 & 75 & 84.15 & 0.12 & 39.48 \\
\hline 23 & 5 & 200 & 6 & 15 & 88.99 & 0.3 & 39.47 \\
\hline 24 & 5 & 225 & 9 & 30 & 90.65 & 0.48 & 39.70 \\
\hline 25 & 5 & 250 & 12 & 45 & 96.16 & 0.34 & 39.66 \\
\hline \multicolumn{7}{|c|}{ Mean S/N Ratio } & 36.87 \\
\hline
\end{tabular}


$\mathrm{S} / \mathrm{N}$ ratio, with a larger-the-better characteristic can be expressed equally:

$$
\eta_{i j=-10 \log }\left(\frac{1}{n} \sum_{j=1}^{n} \frac{1}{y_{i j}^{2}}\right)
$$

where $y_{i j}$ is the $i^{\text {th }}$ response of the $j^{\text {th }}$ experiment, $n$ is the total number of tests.

The $\mathrm{S} / \mathrm{N}$ ratios for the twenty five sets of experiments are also shown in Table 2. The mean yield of JCO FAME and the $\mathrm{S} / \mathrm{N}$ ratio were 70.72 and 36.87 , respectively. The mean values of $\mathrm{S} / \mathrm{N}$ ratio, was evaluated from the influence of the process parameters and the interactions at specific levels, was the average of all the $\mathrm{S} / \mathrm{N}$ ratios of a set of control parameters at a given level are shown Table 2. The contribution of an experimental parameter was calculated from the maximum difference in the values between the mean $\mathrm{S} / \mathrm{N}$ ratios and means (Appendix-i, ii). The order of influence of the parameters in terms of the issue of JCO FAME was: A (catalyst concentration) $>\mathrm{B}$ (reaction temperature $)>\mathrm{D}$ (reaction time) $>\mathrm{C}$ (molar ratio). The effect of $\mathrm{S} / \mathrm{N}$ ratios (Figure 7) is in concordance with the above trend.

Biodiesel production was observed as optimum at $200^{\circ} \mathrm{C}, 5 \%$ Catalyst loading (w/v), $1 \mathrm{~h}$ reaction time and 1/9 oil/methanol molar ratio, average yield of JCO FAME and the S/N ratio were $95.59 \%$ and 39.62 as seen from the Taguchi's method, had been experimentally confirmed with $96 \%$ biodiesel yield in less than an hour in the presence of MBCUS-SrO catalyst. The equation obtained from regression analysis (Table 5) is as listed in Equation (2).

FAME Yield $=20.1+11.5$ Catalyst Percentage + 0.0832 Temperature - 0.0887 Ratio+ 0.0315

Reaction Time (Minute)

This equation signifies that the variable quantities required for the reaction to produce biodiesel could be optimized and catalyst plays the vital role during the reaction to proceed at a faster rate. The other parameters for example reaction temperature, molar ratio of oil to alcohol and reaction time have been prefixed at optimum level reviewing several literature [7, 911, 20-21] in such a way that the role of the catalyst could be found out with distinction.

\subsection{Fuel property analysis of the biodiesel}

The fuel properties of the biodiesel obtained after purification under the optimum set of reaction condition as stated in Taguchi equation was analyzed using appropriate ASTM and European standards. The properties were found equivalent to the biodiesel obtained with MBCUS alone with $96 \%$ conversion of oil to its corresponding esters. Similar conversion efficacy was also demonstrated by Koberg et al. [5]

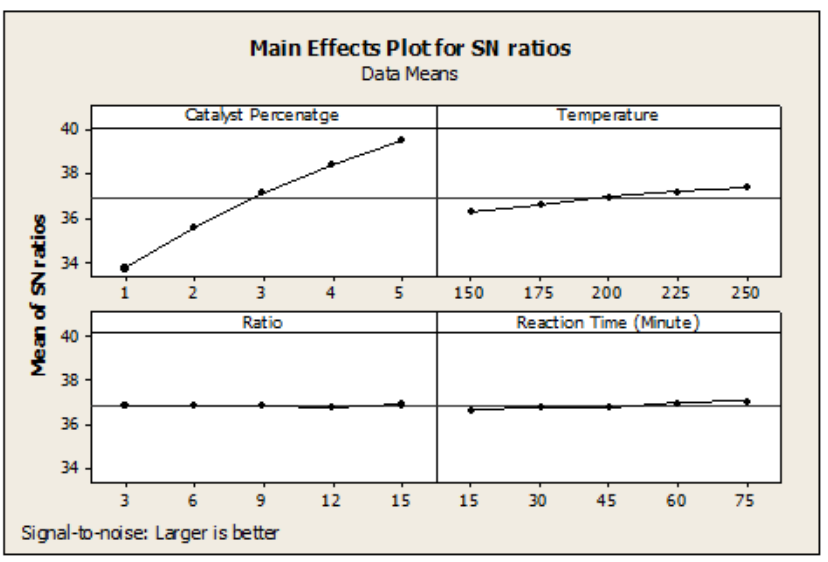

Figure 7. Main effects plot for $\mathrm{S} / \mathrm{N}$ ratios

Table 4. Sequential model sum of squares

\begin{tabular}{lcc}
\hline \multicolumn{1}{c}{ Source } & DF & Seq SS \\
\hline Catalyst Percentage & 1 & 6539.2 \\
Temperature & 1 & 216.2 \\
Alcohol to Oil Molar Ratio & 1 & 3.1 \\
Reaction Time (Minute) & 1 & 12.9 \\
\hline
\end{tabular}

Table 3. Analysis of Variance (ANOVA) for optimum biodiesel yield

\begin{tabular}{lcccccr}
\hline Source & $\begin{array}{c}\text { Degree of } \\
\text { Freedom } \\
(\mathrm{DF})\end{array}$ & $\begin{array}{c}\text { Sum of } \\
\text { Squares (SS) }\end{array}$ & $\begin{array}{c}\text { Mean of Sum } \\
\text { of Squares } \\
\text { (MS) }\end{array}$ & F- Test & P & \\
\hline Regression & 4 & 6771.4 & 1692.8 & 4822.93 & 0 & Significant \\
Residual Error & 20 & 7 & 0.4 & & & \\
\hline Total & 24 & 6778.4 & & & & \\
\hline
\end{tabular}

The SS of parameter added together with SS of residual error to form residual error SS (pooled). 
for cooked oil using pure $\mathrm{SrO}$ as catalyst under microwave irradiation. The free fatty acids were reduced to $2.3 \%$ from $9.2 \%$ originally present in the oil. This is imputable to the raised temperature and internal vapour pressure of the reaction mixture only, not because of catalytic effects because heterogeneous base catalyst has very little impact upon the free fatty acids. This fact was clearly reported in our previous article [9]. The fuel properties of the biodiesel obtained are enlisted in Table 6. These values clearly demonstrate that the biodiesel obtained can be used as substitute of petroleum diesel without further treatment.
The catalyst leaching was observed in the crude FAME layers with MBCUS-SrO which were potassium $9 \mathrm{mg} / \mathrm{kg}$ and sodium 5.0 $\mathrm{mg} / \mathrm{kg}$. This $\mathrm{K}^{+}$leaching is 10 times less than MBCUS alone. The crude FAME was later washed with de-ionized water and dried using molecular sieve (3 $\AA$ ) and carbon column. Thus, after the appropriate washing, treating and centrifugation, the metal concentration in the pure biodiesel was less than $5 \mathrm{mg} / \mathrm{kg}$. From the above discussion it can be concluded that MBCUS-SrO has strongest basic sites and is more efficient between the two, irrespective of pore size, particle size or surface

Table 6. Fuels properties of the biodiesel in comparison to appropriate standards and petro-diesel

\begin{tabular}{|c|c|c|c|}
\hline Properties & Biodiesel Standard & Petro-diesel & FAME \\
\hline Density at $15^{\circ} \mathrm{C}\left(\mathrm{g} \mathrm{cm}^{-3}\right)$ & $0.875-.900$ & $0.820-0.845$ & 0.875 \\
\hline $\mathrm{IBP} / \mathrm{FBP}\left({ }^{\circ} \mathrm{C}\right)$ & & & $308 / 453$ \\
\hline $\begin{array}{l}\text { Distillation characteristics: (\%recovery @330, } \\
360,365,370,427^{\circ} \mathrm{C} \text { ) }\end{array}$ & $90 \% 360$ & $85 \%, 350-95 \%-360$ & $\begin{array}{l}10.0 \\
70.1 \\
80.3 \\
95.5 \\
98.4\end{array}$ \\
\hline Flash point, $\left({ }^{\circ} \mathrm{C}\right)$ & 120 & $52-96$ & 112 \\
\hline Calorific value (MJ kg-1) & 37.25 & 43.1 & 38.35 \\
\hline Viscosity@ $40{ }^{\circ} \mathrm{C}\left(\mathrm{mm}^{2} \mathrm{~s}^{-1}\right)$ & $2.5-6$ & $2-4.5$ & 4.75 \\
\hline Acid Value (mg KOH/g) & 0.50 & - & 4.6 \\
\hline Cetane No & 47.0 & 51.0 & 48.3 \\
\hline Rams bottom carbon residue (wt.\%) max. & 0.300 & 0.300 & 0.280 \\
\hline Copper strip corrosion & 3 & 1 & $1 \mathrm{a}$ \\
\hline Water and Sediment content $\left(\mathrm{mg} \mathrm{kg}^{-1}\right) \max$. & 500 & 200 & 50 \\
\hline Pour Point $\left({ }^{\circ} \mathrm{C}\right) \max$. & Winter +3 and Summer +15 & - & -6 \\
\hline Oxidation stability at $110^{\circ} \mathrm{C}(\mathrm{h}, \mathrm{min})$ & 6 & - & 1.1 \\
\hline Sulphur Content $\left(\mathrm{mg} \mathrm{kg}^{-1}\right)$ max. & 15 & 350 & 4.8 \\
\hline Iodine value ( $\mathrm{g} \mathrm{I}_{2} / 100 \mathrm{~g}$ ) max & 120 & - & 74.5 \\
\hline Sodium (mg kg-1) & 5 & - & 0.1 \\
\hline Potassium (mg kg-1) & 5 & - & 4.8 \\
\hline Total $(\mathrm{Na}+\mathrm{K})\left(\mathrm{mg} \mathrm{kg}^{-1}\right)$ & 5 & - & 4.9 \\
\hline Free Glycerol (\%) $\max$ & 0.2 & - & 0.155 \\
\hline Monoglycerides (\%) max & 0.8 & - & 0.014 \\
\hline Diglycerides (\%) $\max$ & 0.2 & - & 0.000 \\
\hline Triglycerides (\%) max & 0.2 & - & 0.010 \\
\hline Total glycerol (free plus bound) (\%) $\max$ & 0.25 & - & 0.179 \\
\hline Sulfated ash (\%) mass max & 0.02 & - & 0.01 \\
\hline Total contamination & 24 & - & 20 \\
\hline
\end{tabular}

Table 5. Regression analysis of the variables $(\mathrm{R}-\mathrm{Sq}=99.9 \% \quad \mathrm{R}-\mathrm{Sq}(\mathrm{adj})=99.9 \%)$

\begin{tabular}{lccccc}
\hline \multicolumn{1}{c}{ Predictor } & Coef & SE Coef & T & P & \\
\hline Constant & 20.0006 & 0.808 & 24.75 & 0 & Significant \\
Catalyst Percentage & 11.4361 & 0.0838 & 136.49 & 0 & Significant \\
Temperature & 0.083178 & 0.003351 & 24.82 & 0 & Significant \\
Alcohol to Oil Molar Ratio & 0.08288 & 0.02793 & 2.97 & 0 & Significant \\
Reaction Time (Minute) & 0.033832 & 0.005586 & 6.06 & 0 & Significant \\
\hline
\end{tabular}


area. Magnesia modified with $\mathrm{SrO}$ was reported by Yoosuka et al. [22] having improved efficacy similar to MBCUS-SrO. Cetane number of the biodiesel obtained from the JCO was found to be lower than EN standards, but was within the prescribed limit of ASTM standards. The lower value of cetane number is attributed to a high degree of unsaturation and higher percentage of shorter chain fatty acid methyl ester which are primarily formed from the free fatty acids present in the oil $(\sim 9.2 \%)$. This is also concordance to our earlier reported results. The relatively lower value of flash point (115 ${ }^{\circ} \mathrm{C}$ ) is also assigned to the same cause. Nevertheless, these values are in agreement to several other biodiesel obtained from low grade vegetable oil $[2,9,23]$. The reusability of the catalyst was studied and observed that the MBCUS-SrO is much stable than MBCUS alone and can be reused up to 5-time with activation and treating with just a reduction of conversion efficacy of $15 \%$ only.

The significant enhancement of efficacy of MBCUS-SrO to that with MBCUS [9] alone is that the high free fatty acid containing JCO could be converted to esters at relatively low temperature $\left(200{ }^{\circ} \mathrm{C}\right)$ low internal vapor pressure $3.2 \times 10^{6} \mathrm{~Pa}$ as against $275^{\circ} \mathrm{C}$ and $4.2 \times 10^{6}$ $\mathrm{Pa}$ for MBCUS with similar amount of catalyst loading (5 wt.\%). This is attributed to the increase in active basic sites in MBCUS-SrO. Catalyst leaching is reduced with MBCUS-SRO as compared to MBCUS alone, which is another positive attribute in the probe. The novelty of the materials and methods could thus be revealed.

\section{Conclusions}

MBCUS-SrO holds the greatest potential as a heterogeneous catalyst during transesterification of vegetable oil having a high \% of free fatty acid under elevated condition. This catalyst is having plausible advantages over the MBCUS alone in the sense that at relatively low temperature and pressure almost equal conversion efficacy could be held. This is assigned to the active basic sites in the agglomerates of MBCUS-SrO. The monetary value of the pure $\mathrm{SrO}$ catalyst could be trimmed by 5 times. The Taguchi methods and orthogonal array analysis technique provided a really efficient tool for optimizing the process variables during transesterification. The overall optimized conditions unveiled that the catalyst plays a pivotal role during the conversion of oil to biodiesel. The product quality of the biodiesel obtained was very good under optimal operation and having 10 times less potassium and sodium leaching than MBCUS alone. It was also unveiled that either the particle size or the porosity has little impact upon transesterification but the active basic sites and crystalline nature effects much upon the conversion efficacy of the catalyst.

\section{Acknowledgments}

The first author acknowledges Dr B R Ambedkar NIT Jalandhar for the PhD Fellowship and SSS-NIRE for the platform of experimental works. The authors are also thankful to the concerned authority of IOCL, Faridabad for carrying out some of the quality tests of biodiesel and Dr. V C Srivastava, IIT Roorkee, for determining the BET surface area, pore size and pore volume of the catalyst.

\section{References}

[1] Chouhan, A.P.S., Sarma, A.K. (2011). Modern heterogeneous catalysts for biodiesel production: A comprehensive review. Renewable and Sustainable Energy reviews 15: 4378-4399.

[2] Sarma, A.K., Konwer, D., Bordoloi, P.K. (2005). A comprehensive analysis of fuel properties of biodiesel from koroch seed oil. Energy \& Fuels. 19: 656-657.

[3] Satar, I.R., Isahak, N.R.W., Salimon, J. (2015). Characterization of biodiesel from second generation gamma-irradiated Jatropha curcas. Journal of the Taiwan Institute of Chemical Engineers. 49: 85-89.

[4] Zheng, X., Fan, W., Kong, W., Wang, Y., Qi, C. (2014). KF promoted mesoporous $\gamma$ $\mathrm{Al}_{2} \mathrm{O}_{3}$ with strong basicity: Preparation, characterization and catalytic activitiy for transesterification to biodiesel. Kinetics and Catalysis, 55: 592-598.

[5] Koberg, M., Abu-Much, R., Gedanken, A. (2011). Optimization of bio-diesel production from soybean and wastes of cooked oil: Combining dielectric microwave irradiation and a $\mathrm{SrO}$ catalyst. Bioresource Technology 102: 1073-1078.

[6] Chen, C.L., Huang, C.C., Tran, D.T., Chang, J.S. (2013) Biodiesel synthesis via heterogeneous catalysis using modified strontium oxides as the catalysts. Bioresource Technology 113: 8-13.

[7] Atabani, A.E., Silitonga, A.S., Ong, H.C. , Mahlia, T.M.I., Masjuki, H.H., Badruddin, I.A., Fayaz, H. (2013). Non-edible 
vegetable oils: A critical evaluation of oil extraction, fatty acid compositions, biodiesel production, characteristics, engine performance and emissions production. Renewable and Sustainable Energy Review 18: 211-245.

[8] Sivaprakasam, S., Saravanan, C.G. (2007). Optimization of the Transesterification Process for Biodiesel Production and Use of Biodiesel in a Compression Ignition Engine. Energy \& Fuels 21: 29983003.

[9] Sarma, A.K., Kumar, P., Aslam, M., Chouhan, A.P.S. (2014). Preparation and Characterization of Musa balbisiana Colla Underground Stem Nano-material for Biodiesel Production under Elevated Conditions. Catalysis Letters 144: 13441353.

[10] Aslam, M., Saxena, P., Sarma, A.K. (2014). Green Technology for Biodiesel Production From Mesua Ferrea L. Seed Oil. Energy and Environment Research 4: 11-21.

[11] Atadashi, I.M., Aroua, M.K., Abdul Aziz, A.R., Sulaiman, N.M.N. (2012). The effects of water on biodiesel production and refining technologies: A review. Renewable and Sustainable Energy Reviews 16: 3275-3470.

[12] Mahamuni, N.N., Adewuyi, Y.G. (2009). Optimization of the Synthesis of Biodiesel via Ultrasound-Enhanced BaseCatalyzed Transesterification of Soybean Oil Using a Multifrequency Ultrasonic Reactor. Energy \& Fuels 23: 2757-2766.

[13] Sharma, M., Khan, A.A., Puri, S.K., Tuli, D.K. (2012). Wood ash as a potential heterogeneous catalyst for biodiesel synthesis. Biomass Bioenergy 41: 94-106.

[14] Kuwahara, Y., Tsuji, K., Ohmichi, T., Kamegawa, T., Mori, K., Yamashita, H. (2012). Transesterifications using a hydrocalumite synthesized from waste slag: an economical and ecological route for biofuel production. Catalyst Science and Technology 2: 1842-1851.

[15] Istadi, I., Anggoro, D.D., Buchori, L., Utami, I., Solikhah, R. (2012). Process Parameters Optimization of Potential $\mathrm{SO}_{4}{ }^{2-/ Z n O}$ Acid Catalyst for Heterogeneous Transesterification of Vegetable Oil to Biodiesel. Bulletin of Chemical Reac- tion Engineering \& Catalysis, 7(2): 150157 (doi:10.9767/bcrec.7.2.4064.150-157)

[16] Mahamuni, N.N., Adewuyi, Y.G. (2010). Application of Taguchi Method to Investigate the Effects of Process Parameters on the Transesterification of Soybean Oil Using High Frequency Ultrasound. Energy \& Fuels 24: 2120-2126.

[17] Chouhan, A.P.S., Sarma, A.K. (2013). Biodiesel production from Jatropha curcas L. oil using Lemna perpusilla Torrey ash as heterogeneous catalyst. Biomass Bioenergy 55: 386-389.

[18] Deka, D.C., Basumatary, S. (2011). High quality biodiesel from yellow oleander (Thevetia peruviana) seed oil. Biomass Bioenergy. 35: 1797-1803.

[19] Hassan, S., Vinjamur, M. (2014). Concentration-independent rate constant for biodiesel synthesis from homogeneous-catalytic esterification of free fatty acid. Chemical Engineering Science 107: 290-301.

[20] White, K., Lorenz, N., Potts, T., Penney, W.R., Babcock, R., Hardison, A., Canuel, E.A, Hestekin, J.A. (2011). Production of biodiesel fuel from tall oil fatty acids via high temperature methanol reaction. Fuel 90: 3193-3199.

[21] Moreno, P.J.G., Khanum, M., Guadix, A., Guadix, E.M. (2014). Optimization of biodiesel production from waste fish oil Renewable Energy 68: 618-624.

[22] Yoosuk, B.P., Krasae, B., Puttasawat, P., Udomsap, N., Viriya-empikul, Faungnawakij, K.F. (2010). Magnesia modified with strontium as a solid base catalyst for transesterification of palm olein. Chemical Engineering Journal 162: 58-66.

[23] Ong, H.C., Silitonga, A.S., Masjuki, H.., Mahlia, T.M.I., Chong, W.T. (2013). Production and comparative fuel properties of biodiesel from non-edible oils: Jatropha curcas, Sterculia foetida and Ceiba pentandra. Energy Conversion and Management. 73: 245-255.

[24] Chena, C.L., Huangb, C.C., Tran, D.T., Changa, J.S. (2012). Biodiesel synthesis via heterogeneous catalysis using modified strontium oxides as the catalysts. Bioresource Technology 113: 8-13. 